\title{
Síndrome de Brown bilateral associada com hipermobilidade articular benigna: relato de caso
}

\author{
Bilateral Brown's syndrome associated with benign joint hypermobility: \\ a case report
}

\author{
David Kirsch ${ }^{1}$ \\ Carolina Ayres Vilarinho Corrêa Lima² \\ Miriam Mina Yamamoto ${ }^{3}$ \\ Eric Pinheiro Andrade ${ }^{4}$ \\ Márcia Ferrari Perez ${ }^{5}$
}

\begin{tabular}{|l|}
\hline RESUMO \\
\hline A síndrome de Browné caracterizada por grande limitação de elevação em \\
adução, elevação ligeiramente diminuída ou normal na abdução, ani- \\
sotropia em "Y" ou "V", intorção do olho em supraversão e ducção forçada \\
positiva. Sua causa se deve à inelastibilidade do músculo oblíquo superior \\
ou por sua contenção em sua própria bainha. A hipermobilidade articular \\
benigna é doença hereditária do tecido conectivo caracterizada por \\
aumento da mobilidade em diversas articulações. Sua prevalência é muito \\
variável em relação à idade, sexo e etnia, variando de 2 a 35\% em homens \\
e de 5 a 57\% e mulheres. Neste relato os autores descrevem um caso de \\
síndrome de Brown associada com hipermobilidade articular benigna e \\
atentam para a associação pouco referida na literatura. J.C.S, masculino, \\
6 anos de idade, pardo, estudante, foi encaminhado à Universidade de \\
Santo Amaro com queixa de exotropia há dois anos que aumentava na \\
supraversão. Paciente com o diagnóstico de síndrome de Brown bilateral \\
teve o diagnóstico de hipermobilidade articular benigna pelo Reumatolo- \\
gista. O paciente com hipermobilidade articular benigna pode desenvol- \\
ver sintomas articulares como artralgia devido a uma inflamação articular. \\
Acreditamos na possibilidade de que síndrome de Brown possa ter \\
ocorrido devido a processo inflamatório na tróclea que teve início devido \\
a hipermobilidade articular benigna.
\end{tabular}

Descritores: Transtornos da motilidade ocular/diagnóstico; Instabilidade articular; Estrabismo; Relatos de casos [Tipo de publicação]

\section{INTRODUÇÃO}

A síndrome de Brown, ou síndrome da bainha do tendão do oblíquo superior foi descrita pela primeira vez, em 1950, pelo oftalmologista Harold $\mathbf{W}^{(1)}$.

É caracterizada por grande limitação de elevação em adução, elevação ligeiramente diminuída ou normal na abdução, anisotropia em "Y" ou "V", intorção do olho em supraversão e ducção forçada positiva ${ }^{(1)}$.

Sua causa se deve à inelastibilidade do músculo oblíquo superior ou por sua contenção em sua própria bainha ${ }^{(1)}$.

Ocorre em um para cada 400 a 450 pacientes estrábicos (Estados Uni$\operatorname{dos})^{(2)}$, com maior incidência nas mulheres $(55 \%)$, maior envolvimento do olho direito $(66 \%)$, sendo sua forma bilateral rara (10-18\% dos casos $)^{(3)}$.

Pode ser dividida em congênita e adquirida. A adquirida apresenta como causas processos inflamatórios da tróclea ou do tendão como miosites, pós-operatórios, artrite reumatóide juvenil e do adulto, lupus eritematoso sistêmico, cisticercose muscular ${ }^{(4)}$ ou um processo inflamatório idiopático. Assim como massas orbitais nasais superiores. 
A hipermobilidade articular benigna é uma doença hereditária do tecido conectivo caracterizada por um aumento da mobilidade em diversas articulações. Sua prevalência é muito variável em relação à idade, sexo e etnia, variando de 2 a $35 \%$ em homens e de 5 a $57 \%$ em mulheres ${ }^{(5)}$.

Seu diagnóstico é feito clinicamente através do sistema Beighton de 9 pontos desenvolvido em 1973, no qual, cada um dos seguintes sinais vale 1 ponto, num total de 9: flexão dorsal do quinto dedo até noventa graus, encostar o polegar em seu antebraço, hiperestender o joelho a mais de 10 graus, hiperestender o cotovelo a mais de 10 graus e encostar as mãos no chão sem dobrar o joelho ${ }^{(5)}$.

Pode estar relacionada ainda a alterações em pulmões, coração, vísceras abdominais, pélvicas e olhos ${ }^{(6)}$.

Neste relato os autores descrevem um caso de síndrome de Brown associada com hipermobilidade articular benigna e atentam para a associação pouco referida na literatura.

\section{RELATO DE CASO}

J.C.S, masculino, 6 anos de idade, pardo, estudante, foi encaminhado ao setor de Motilidade Extrínseca Ocular da Universidade de Santo Amaro - UNISA com queixa de exotropia há dois anos que aumentava na supraversão. Negava ter realizado oclusão, correção óptica, cirurgias prévias ou trauma.

De antecedentes pessoais referia ter nascido de parto normal, a termo, sem intercorrências na gestação. Apresentava desenvolvimento neuro-psico-motor compatível com a idade. Negava outros casos de estrabismo na família.

Ao exame oftalmológico apresentava acuidade visual (sem correção) de 1,0 em ambos os olhos, reflexos pupilares motores e consensuais normais (longe e perto), mapeamento de retina dentro dos padrões da normalidade em ambos os olhos. A refração estática subjetiva mostrou $+0,25 \mathrm{DE}$ no olho direito e plano DE $+0,50 \mathrm{DC} 90^{\circ}$ no olho esquerdo, acuidade visual de 1,0 em ambos os olhos. Apresentava Titmus de 40', de arco, com ausência de torcicolo.

Ao teste de cobertura com prismas (sem correção) apresentou ortotropia na posição primária do olhar e infraversão (longe e perto), e exotropia de 30 dioptrias prismáticas na supraversão (Figura 1). Nas versões notou-se hipofunção do músculo oblíquo inferior direito de -4 , do músculo oblíquo inferior esquerdo de -3, não havendo hipofunção dos músculos retos verticais, ou hiperfunção do músculo oblíquo superior bilateralmente (Figura 1 ).

O mapeamento de retina revelou, em ambos os olhos, em supraversão a mácula posicionada obliquamente ao disco óptico, o que não se repetiu nas outras posições do olhar, demonstrando inciclotorção em supraversão.

Foi feita hipótese diagnóstica de síndrome de Brown bilateral, confirmada com restrição na ducção passiva, e positividade da ducção forçada. As ducções passivas foram realizadas sob anestesia tópica, com excelente colaboração do paciente.

Devido sua queixa ser de aproximadamente dois anos, foram pesquisadas causas de síndrome de Brown adquirido. Foi solicitada tomografia computadorizada das órbitas que afastou qualquer processo compressivo, e demonstrou um oblíquo superior espessado (Figura 2).

Foi solicitada avaliação do serviço de reumatologia da nossa universidade, que afastou artrite reumatóide juvenil e lupus eritematoso sistêmico, porém diagnosticou uma hipermobilidade articular benigna, com 9 pontos no Beighton Score (Figura 3).

Foi prescrito como tratamento: Advil ${ }^{\mathrm{R}}$ (Ibuprofeno - antiinflamatório não hormonal), $10 \mathrm{mg} / \mathrm{kg} / \mathrm{dose}, 3$ vezes por dia por 1 mês, sem melhora do quadro clínico.

O paciente continua sendo acompanhado em nosso serviço, mantendo o mesmo quadro clínico há um ano.

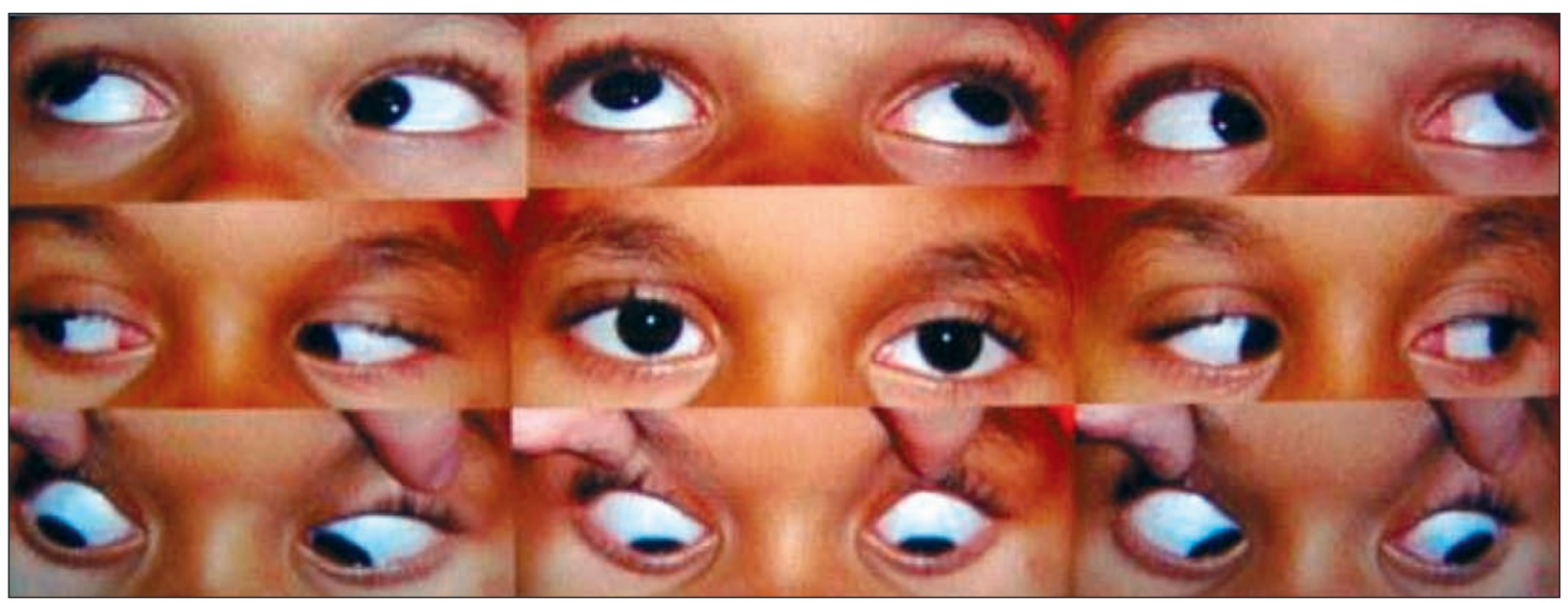

Figura 1 - Versões do paciente, mostrando exotropia em supraversão e hipofunção bilateral do músculo oblíquo inferior 


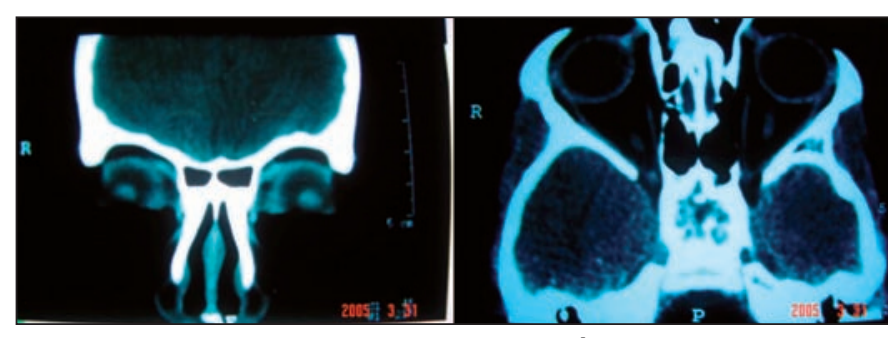

Figura 2 - Tomografia computadorizada de órbita, mostrando espessamento bilateral do músculo oblíquo superior

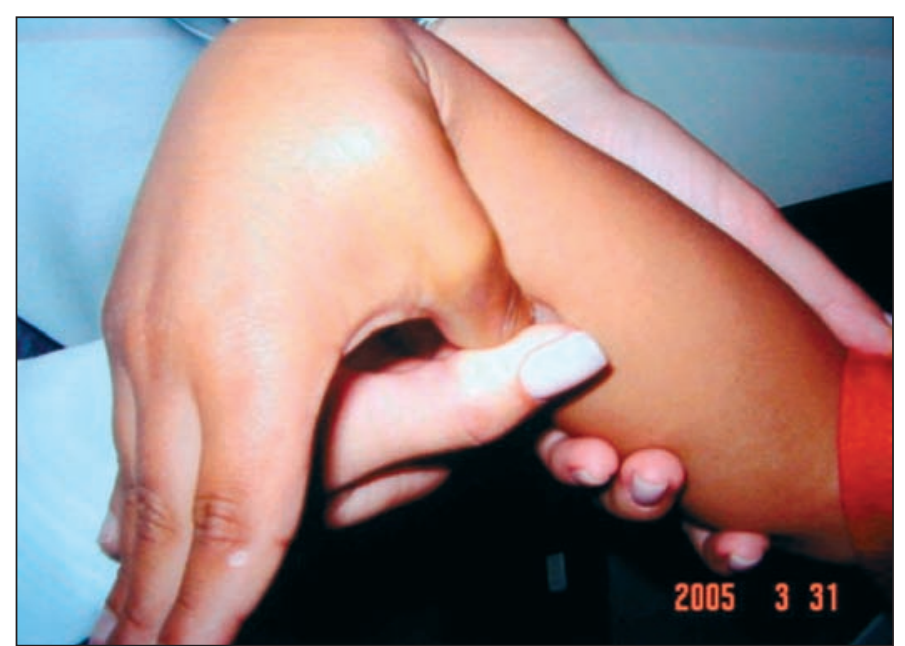

Figura 3 - Paciente encostando o polegar direito em seu antebraço, sinal que determina 1 ponto no "Sistema Beighton de 9 pontos" Pontuação que faz o diagnóstico da hipermobilidade articular benigna.

\section{DISCUSSÃO}

O caso apresentado é de uma síndrome de Brown bilateral adquirida (devido ao fato do pai do paciente ser bom informante e assegurar que o desvio se iniciou há dois anos) e de provável etiologia inflamatória (demonstrado pelo espessamento do oblíquo superior na tomografia computadorizada da órbita). Contudo a causa dessa inflamação ainda é incerta. Além do quadro oftalmológico, o paciente tem o diagnóstico de hipermobilidade articular benigna, uma doença do tecido conectivo caracterizada pelo aumento da mobilidade em diversas articulações e repercussões em vários outros órgãos tais como coração, vísceras pélvicas, vísceras abdominais e olhos ${ }^{(5)}$. O paciente com hipermobilidade articular benigna pode ainda desenvolver sintomas articulares como artralgia devido a uma inflamação articular.

Em 1996 Mishra et al., avaliaram 34 pacientes com síndrome da hipermobilidade articular benigna procurando caracterizar as alterações extra-articulares. Foi realizado o exame oftalmológico completo e notou-se flacidez palpebral como a principal alteração encontrada (41\%), além de um caso de exotropia ${ }^{(6)}$.

Acreditamos na possibilidade de que síndrome de Brown possa ter ocorrido devido a um processo inflamatório na tróclea que teve início pela hipermobilidade articular benigna.

Foi realizado o tratamento com antiinflamatório não hormonal $^{(2)}$, sem melhora. É descrita também injeção de corticoeste- róides na tróclea, entretanto pela necessidade de se realizar anestesia geral em nosso paciente (por ele apresentar 6 anos de idade) foi optado por não fazê-lo.

Várias cirurgias foram descritas para a síndrome de Brown como a tenotomia ${ }^{(7)}$, luxação do músculo oblíquo superior na tróclea, e expansão do tendão do músculo oblíquo superior com silicone ${ }^{(8)}$, porém, no presente caso não havia indicação cirúrgica pela ausência de torcicolo ou um desvio vertical que prejudicasse sua qualidade de vida.

\section{ABSTRACT}

Brown's syndrome is characterized by a limitation of elevation in adduction, slight or normal limitation of elevation in abduction, divergence in straight upgaze (V-pattern), intorsion in upgaze and positive forced duction. It is caused by a tight or inelastic superior oblique tendon. Benign joint hypermobility is a hereditary disease of the connective tissue characterized by an increase of mobility in diverse joints. Its prevalence is very changeable regarding age range, sex and ethnicity, varying from 2 to $35 \%$ in men and 5 to $57 \%$ in women. In this case the authors describe a case of Brown's syndrome associated with Benign joint hipermobility and call attention to a little described association in the literature. J.C.S, male, 6 years old, mulatto, student, was referred to the University of Santo Amaro with complaint of exotropia for 2 years that it increased in supraversion. The patient with the diagnosis of bilateral Brown's syndrome, was diagnosed as having benign joint hipermobility by the reumatologist. The patient with benign joint hipermobility can develop symptoms such as arthralgia caused by a joint inflammation. We believe in the possibility that Brown syndrome has occurred, caused by an inflammatory process in the trochlea that started because of the benign joint hypermobility.

Keywords: Ocular motility disorders/diagnosis; Joint instability; Strabismus; Case reports [Publication type]

\section{REFERÊNCIAS}

1. Souza-Dias CR. Síndromes especiais da motilidade ocular. In: Souza-Dias CR, Almeida GV, organizadores. Estrabismo: Manual CBO. Rio de Janeiro: Cultura Médica; 1999. p.135-6.

2. Wright K. Brown syndrome [text on the Internet]. [cited 2005 Mai 26]. Available from: http://www.emedicine.com/oph/topic552.htm.

3. Cabello Miguel C, Puertas Bordallo D, Villafruela Güemes IM, Jiménez Serrano C, Veiga de La Jara C. Estudio retrospectivo del Síndrome de Brown congénito. Evolución clínica. Acta Estrabol [serial on the Internet]. 1998 [about 5 p.]. Available form: http://www.oftalmo.com/estrabologia/rev-98/98-25.htm.

4. Pandey PK, Chaudhuri Z, Bathia A. Extraocular muscle cysticercosis presenting as Brown syndrome. Am J Ophthalmol. 2001;131(4):526-7.

5. Hakim A, Grahame R. Joint hypermobility. Best Pract Res Clin Rheumatol. 2003;17(6):989-1004. Review.

6. Mishra MB, Ryan P, Atkinson P, Taylor H, Bell J, Calver D, et al. Extraarticular features of benign joint hypermobility syndrome. Br J Rheumatol. 1996;35(9):861-6.

7. Maggi R, Maggi C. Tendon surgery in Brown's syndrome. J Pediatr Ophtalmol Strabismus. 2002;39(1):33-8.

8. Wright KW. Superior oblique silicone expander for Brown syndrome and superior oblique overaction. J Pediatr Ophtalmol Strabismus. 1991;28(2):101-7. 